\title{
Management of Cracked Teeth: A Report of Two Cases
}

\author{
${ }^{1}$ Nagarajan Geethapriya, ${ }^{2}$ Arunajatesan Subbiya, ${ }^{3}$ Suresh Mitthra, ${ }^{4}$ Paramasivam Vivekanandhan
}

\begin{abstract}
Cracked tooth is an incomplete crack running in the crown of the tooth starting from the cervical portion. The crack may be initiated by excessive masticatory force or unintentional bruxism. Initially, they do not present with any symptoms, but later, these cracked teeth develop pain and sensitivity, which requires treatment. Here, we have presented two case reports diagnosed as cracked teeth, which were managed successfully by root canal treatment. The cases were followed up and the patients are asymptomatic. This proves that root canal treatment is a viable choice of treatment for cracked teeth.
\end{abstract}

Keywords: Cracked tooth, Hypersensitivity, Masticatory force, Root canal treatment.

How to cite this article: Geethapriya N, Subbiya A, Mitthra S, Vivekanandhan P. Management of Cracked Teeth: A Report of Two Cases. J Oper Dent Endod 2018;3(1):48-51.

Source of support: Nil

Conflict of interest: None

\section{INTRODUCTION}

A cracked tooth is an incomplete crack originating on the clinical crown that extends cervically. Though it was erroneously referred to as "cracked tooth syndrome," it is now described as cracked tooth. It is described as "A fracture plane of unknown depth and direction passing through tooth structure that, if not already involving, may progress to communicate with the pulp and or periodontal ligament."1 They may be seen in both intact teeth and restored teeth and usually run in the mesiodistal direction. The incidence of cracked teeth seems to have increased in the last few decades. This could be because that it is being diagnosed more than before with increase in awareness among dentists according to Bader et al. ${ }^{2}$

The most common cause is excessive masticatory force, which could be either bruxism or unintentional biting on a small and very hard object. Other reason could be a sudden impact from an accidental trauma. Though in the initial stages, a cracked tooth may not present any

\footnotetext{
${ }^{1}$ Senior Lecturer, ${ }^{2}$ Professor and Head, ${ }^{3}$ Reader, ${ }^{4}$ Professor

${ }^{1-4}$ Department of Conservative Dentistry and Endodontics, Sree Balaji Dental College \& Hospital, Chennai, Tamil Nadu, India

Corresponding Author: Arunajatesan Subbiya, Professor and Head, Department of Conservative Dentistry and Endodontics Sree Balaji Dental College \& Hospital, Chennai, Tamil Nadu India, Phone: +914424425809, e-mail: drsubbiya@gmail.com
}

symptoms except for a crack, which may or may not be visible either in naked eye, magnification, transillumination, etc. It may develop a nonspecific symptom, such as pain on biting. If left untreated, a cracked tooth can become a split tooth and have a hopeless prognosis and may have to be extracted. Endodontic treatment is the treatment of choice to salvage a symptomatic tooth diagnosed with irreversible pulpitis or pulp necrosis. But a cracked tooth represents a treatment dilemma for the clinician as it presents vague symptoms and unpredictable prognosis. In such teeth, which present with hypersensitivity to thermal stimuli and pulpal and periapical pathology, the endodontic prognosis is guarded and extraction is usually the option..$^{3,4}$ The aim of this case report is to present two cases of endodontic management of cracked tooth with a follow-up of at least 4 years.

\section{CASE REPORTS}

\section{Case 1}

A 40-year-old female patient reported with the chief complaint of pain and sensitivity in the right lower back tooth region. Pain was sharp and intermittent in nature and increased on mastication. The medical history was noncontributory. Clinical examination revealed a small crack running in the mesiodistal direction on the mesial aspect of 46 (Fig. 1). The presence of a crack was confirmed using transillumination test. Radiographic interpretation showed mild periapical radiolucency in 46 (Fig. 2). The treatment plan was to perform root canal treatment followed by crown in 46 .

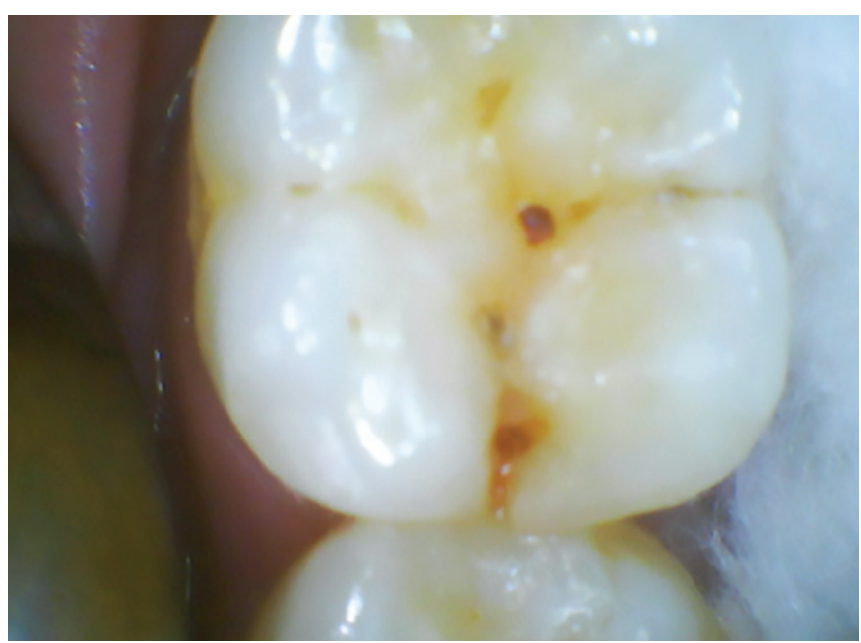

Fig. 1: Clinical photograph—case 1 


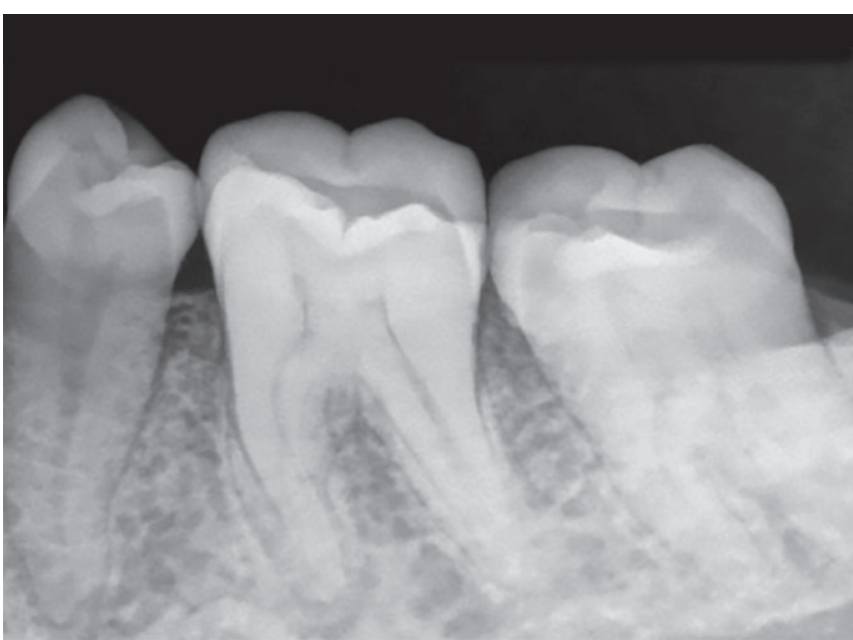

Fig. 2: Diagnostic radiograph—case 1

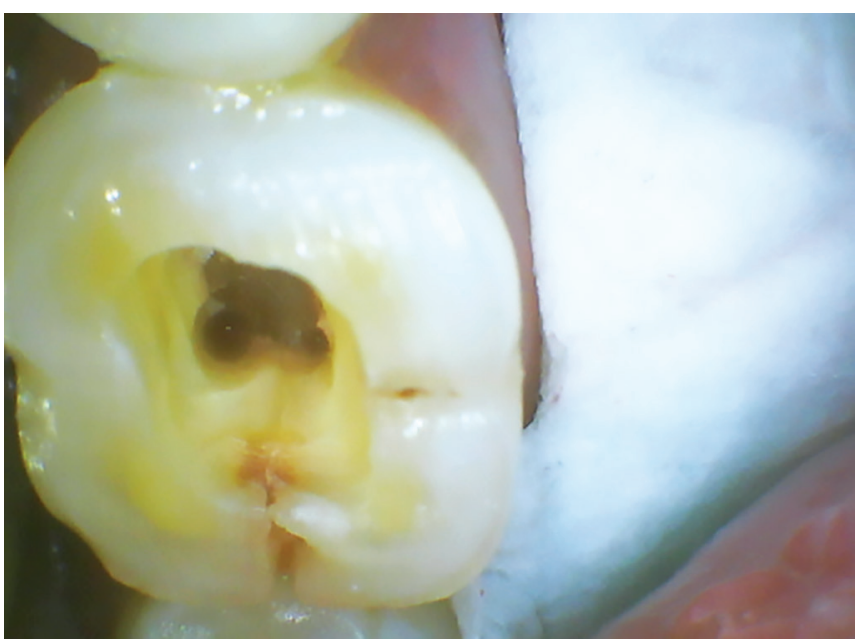

Fig. 4: Access cavity preparation—case 1

Tooth no. 46 was anesthetized. Access cavity preparation was done under rubber dam isolation using endoaccess bur and four canals were located (Fig. 3). Two canals were located on the mesial aspect and two canals on the distal aspect. The access cavity picture clearly shows the crack propagation in 46 in the mesiodistal direction (Fig. 4). Cleaning and shaping were done with Mtwo rotary file system up to 0.06 taper. Obturation was done with AH plus as sealer. The crack was reinforced with bonded composite restoration and the tooth was disoccluded (Fig. 5). Later metal-ceramic crown was placed.

The case was followed up for 4 years and the recent radiograph shows no periapical abnormalities and the patient is asymptomatic.

\section{Case 2}

A 35-year-old male patient reported with the chief complaint of severe pain in the right upper back tooth region. Pain was sharp and increased on chewing hard substances. The patient's medical history was noncontributory. On

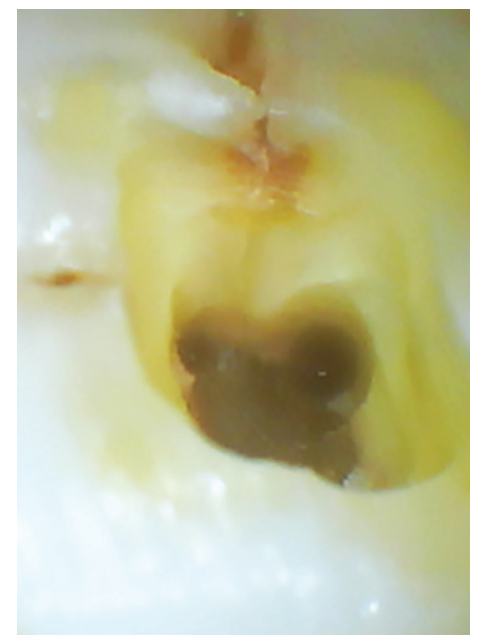

Fig. 3: Access cavity preparation—case 1

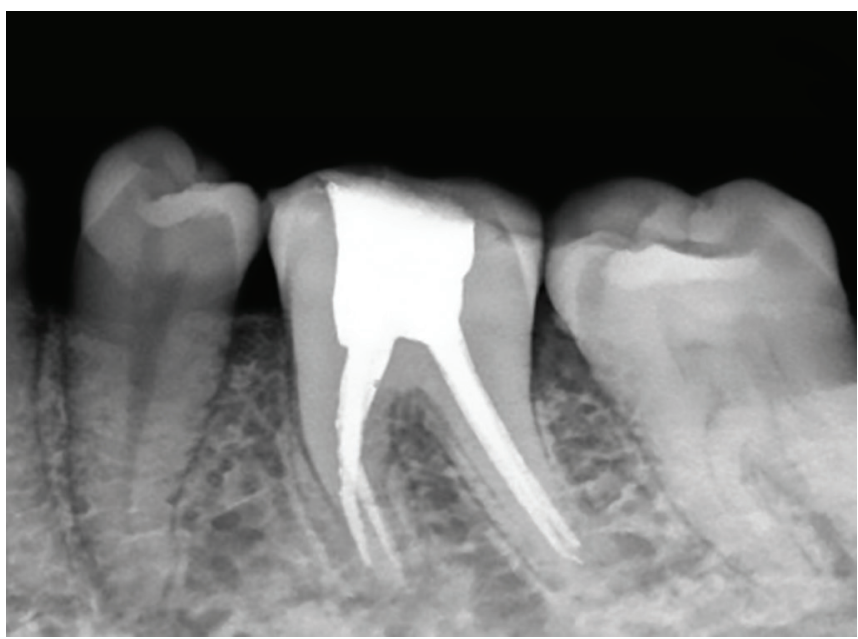

Fig. 5: Postoperative radiograph—case 1

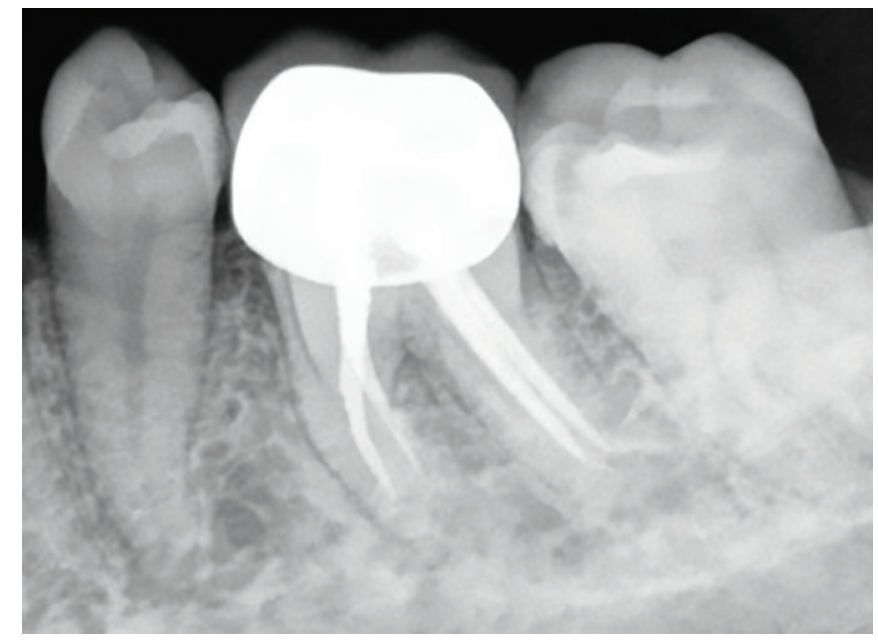

Fig. 6: After crown placement-case 1

careful clinical examination, a crack was seen propagating in the mesiodistal direction in 16 (Fig. 6). Radiographic examination did not show any periapical radiolucency (Fig. 7). Root canal treatment followed by crown was the proposed treatment plan. 


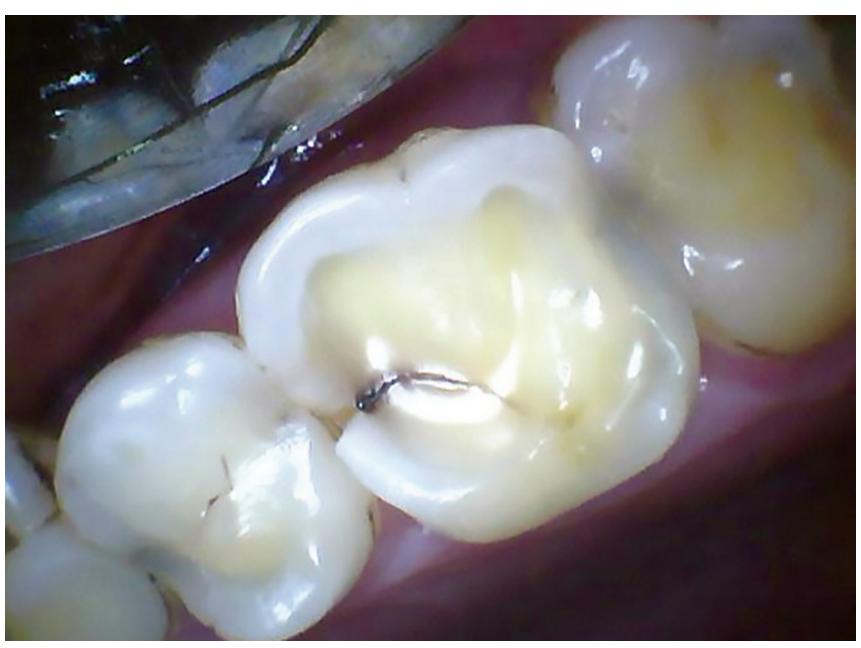

Fig. 7: Clinical photograph—case 2

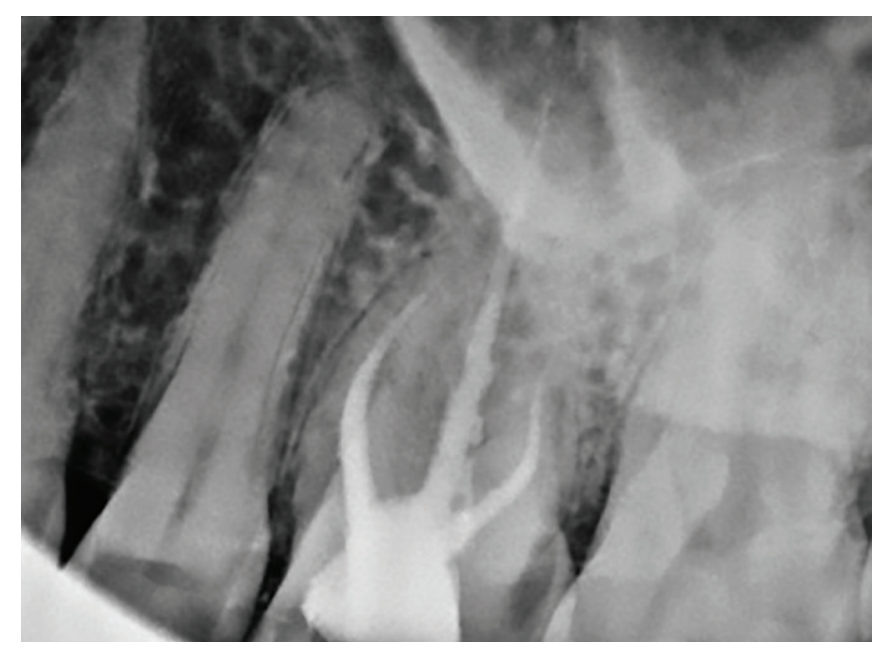

Fig. 9: Post-operative radiograph—case 2

Local anesthesia was administered and access cavity was prepared under rubber dam isolation. Canals were located, and cleaning and shaping were done with Mtwo rotary file system until size 250.06 taper in the buccal canals and size 300.06 taper in the palatal canals. Canals were obturated with AH plus as sealer. The crack was reinforced with bonded composite restoration and the tooth was relieved from occlusion (Fig. 8). Metal-ceramic crown was placed in the next visit (Fig. 9). The patient was asymptomatic on 1 year follow-up (Fig. 10).

\section{DISCUSSION}

The treatment plans and success rate of cracked teeth depend on the extent and location of the cracks and also upon the severity of the symptoms. ${ }^{5}$ If the size of the involved portion of the tooth is relatively small and the crack does not involve the pulp, the tooth could be restored conventionally using resins, inlays, or crowns with periodic follow-ups. ${ }^{3}$ If the crack is extensive with prolonged symptoms, thermal hypersensitivity, and

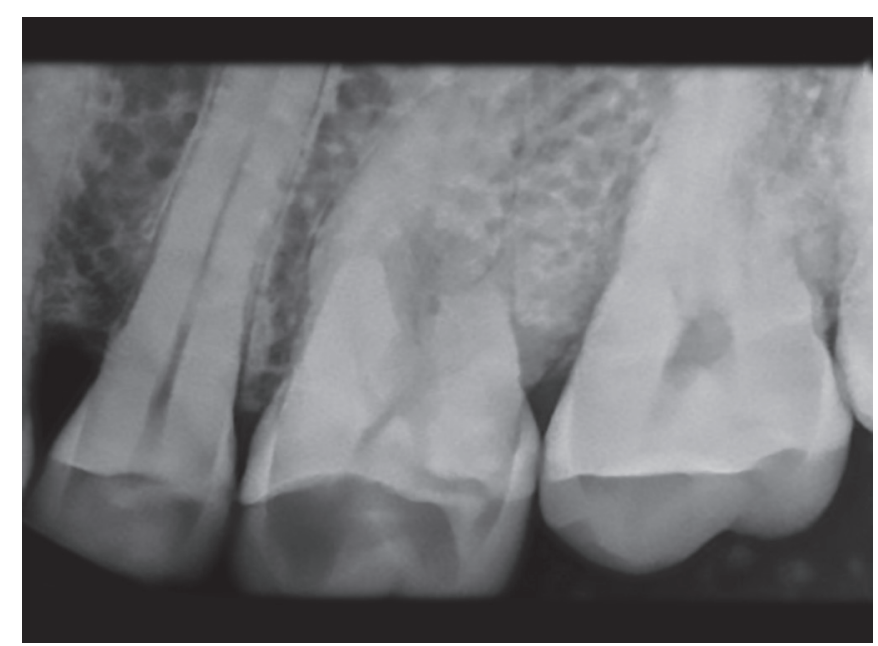

Fig. 8: Diagnostic radiograph—case 2

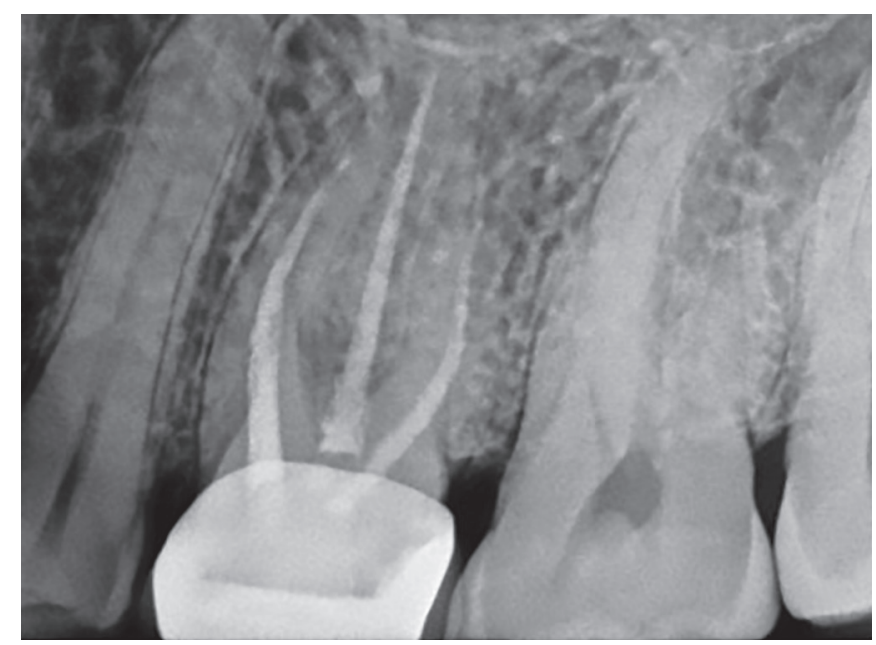

Fig. 10: One-year follow-up—case 2

pulpal and periapical pathology, root canal treatment is the treatment of choice followed by crown placement and continuous follow-up. In our case, there was sharp and intermittent pain, which increased on mastication, and the crack was also extensive, which could be observed on the pulpal floor in the prepared access cavity. There are some cases in which the crack crosses the pulpal floor, extends deep into the bone, or symptoms persist even after root canal treatment; in such situations, extraction is usually the only viable option. ${ }^{3,4}$ As per the previous studies, the prevalence of cracked teeth is mainly observed in patients aged 30 to 50 years. ${ }^{6-8}$ Both of our patients were aged between 30 and 50 years.

The fatigue resistance of human dentin is inversely proportional to the age factor. As age increases, fatigue resistance $^{4}$ and dentin elasticity ${ }^{9}$ decrease. According to Kang et al, ${ }^{10}$ lower second molars were the most commonly affected teeth followed by lower first molars. The high incidence of cracks in the lower second molars may be related to their proximity to the temporomandibular joint. ${ }^{3,11}$ Among our cases, one was lower first molar. 
The masticatory force may be larger on the tooth, which is closer to the temporomandibular joint due to the lever effect. The lingual cusps of maxillary molars may also function as plungers, which may cause structural fatigue in the lower antagonists. Moreover, mandibular molars have a deeper central fossa when compared with maxillary molars. They also have the oblique ridge, which reinforces the tooth by itself and increases resistance to crack formation. ${ }^{12,13}$ All these reasons make mandibular molars the most susceptible candidates to develop cracks.

High incidence of cracks has been reported in heavily restored teeth, ${ }^{9}$ unrestored teeth, ${ }^{12}$ teeth with untreated carious lesions, ${ }^{13}$ thermal cycling, and parafunctional habits. ${ }^{6}$ In our cases, both the teeth were unrestored. Cracks have also been reported in teeth restored with gold inlays, which may be due to the sharp internal angle required for the retention of the material. Amalgam $\left(22-28 \mathrm{ppm} /{ }^{\circ} \mathrm{C}\right)$ and gold $\left(14.20 \mathrm{ppm} /{ }^{\circ} \mathrm{C}\right)$ have relatively large thermal expansion coefficients. The mismatch in thermal expansion coefficients between the tooth and the restoration may produce crack, when there is rise in temperature. This is because, when there is increase in temperature, the restorative material will expand more than the tooth, which will ultimately result in crack initiation in the tooth in an attempt to cope with the expansion of the restorative material.

Tooth slooth is a special plastic bite block, which is a valuable diagnostic tool in diagnosing cracks by applying force to a specific cusp. Most of the cases with cracked teeth have severe cold sensitivity and a large proportion of teeth are nonvital. Pulp necrosis can be caused by cracks, which is termed as "fracture necrosis." ${ }^{\text {"14 }}$ Early diagnosis may help to maintain pulp vitality and prevent the propagation of cracks.

Another prognostic factor that can indicate the survival rate of the tooth is the probing depth. A deep probing depth indicates that the crack can progress deep into the root and can adversely affect the periodontal support eventually leading to tooth loss. ${ }^{15}$ Studies have reported that cracked teeth with probing depths of $>4$ $\mathrm{mm}$ have poor prognoses and that the proportion of teeth requiring root canal treatment also increases with increasing probing depths. ${ }^{16}$
Root canal treatment is a viable nonsurgical treatment option for salvaging cracked teeth. Though information regarding survival rates of root-filled cracked teeth and prognosis assessment are scarce, our case has a good survival rate with a 4-year follow-up and the patient is asymptomatic. Thus, root canal treatment followed by crown serves as a viable treatment option for cracked teeth depending upon the extent of the crack with good success rates.

\section{REFERENCES}

1. Ellis SG. Incomplete tooth fracture-proposal for a new definition. Br Dent J 2001 Apr;190(8):424-428.

2. Bader JD, Martin JA, Shugars DA. Incidence rates for complete cusp fracture. Community Dent Oral Epidemiol 2001 Oct;29(5):346-353.

3. Lynch CD, McConnell RJ. The cracked tooth syndrome. J Can Dent Assoc 2002 Sep;68(8):470-475.

4. Lubisich EB, Hilton TJ, Ferracane J; Northwest Precedent. Cracked teeth: a review of the literature. J Esthet Restor Dent 2010 Jun;22(3):158-167.

5. Türp JC, Gobetti JP. The cracked tooth syndrome: an elusive diagnosis. J Am Dent Assoc 1996 Oct;127(10):1502-1507.

6. Roh BD, Lee YE. Analysis of 154 cases of teeth with cracks. Dent Traumatol 2006 Jun;22(3):118-123.

7. Snyder DE. The cracked-tooth syndrome and fractured posterior cusp. Oral Surg Oral Med Oral Pathol 1976 Jun;41(6): 698-704.

8. Udoye CI, Jafarzadeh H. Cracked tooth syndrome: characteristics and distribution among adults in a Nigerian teaching hospital. J Endod 2009 Mar;35(3):334-336.

9. Seo DG, Yi YA, Shin SJ, Park JW. Analysis of factors associated with cracked teeth. J Endod 2012 Mar;38(3):288-292.

10. Kang SH, Kim BS, Kim Y. Cracked teeth: distribution, characteristics, and survival after root canal treatment. J Endod 2016 Apr;42(4):557-562.

11. Ehrmann EH, Tyas MJ. Cracked tooth syndrome. Aust Dent J 1990 Aug;35(4):390-391.

12. Hiatt WH. Incomplete crown-root fracture in pulpalperiodontal disease. J Periodontol 1973 Jun;44(6):369-379.

13. Rosen H. Cracked tooth syndrome. J Prosthet Dent 1982 Jan;47(1):36-43.

14. Berman LH, Kuttler S. Fracture necrosis: diagnosis, prognosis assessment, and treatment recommendations. J Endod 2010 Mar;36(3):442-446.

15. Tan L, Chen NN, Poon CY, Wong HB. Survival of root filled cracked teeth in a tertiary institution. Int Endod J 2006 Nov;39(11):886-869.

16. Kim SY, Kim SH, Cho SB, Lee GO, Yang SE. Different treatment protocols for different pulpal and periapical diagnoses of 72 cracked teeth. J Endod 2013 Apr;39(4):449-452. 